\title{
Extensão universitária: contribuições de professores guarani para a formação inicial de professores de matemática
}

\author{
University extension: guarani teachers' contributions to an initial training of math teachers
}

Gabriela dos Santos Barbosa*

\section{Resumo}

O objetivo deste artigo é analisar as contribuições de um projeto de extensão universitária voltado à formação continuada de professores guarani para a formação inicial de professores de matemática. O projeto foi desenvolvido com professores indígenas que atuam em duas aldeias guarani situadas em Maricá, Rio de Janeiro, e contou com a participação de dois estudantes de licenciatura em Matemática, bolsistas de extensão. Seguindo os princípios da Pedagogia Decolonial, buscou-se compreender os impactos da interação com os professores indígenas e com a cultura guarani na formação dos estudantes de licenciatura. Tratou-se de um estudo de caso fundamentado nas ideias de D’Ambrósio (1997, 1998, 2002, 2013) sobre Etnomatemática, nas ideias de Tardif (2014) sobre os saberes docentes e de Serrazina (2003), Alarcão (2001) e Nóvoa (2009) sobre formação de professores. Ao longo do projeto, implementaram-se ações que evidenciaram aspectos da cultura guarani. Incentivou-se o desenvolvimento da postura investigativa dos professores por meio da análise de suas práticas e da reflexão sobre o desempenho de seus alunos. Acompanhando tais ações, os licenciandos puderam rever sua concepção de matemática e de educação matemática. Entre os principais resultados, estão a crítica feita por eles aos saberes de formação e saberes disciplinares propostos pela universidade e a relativização de saberes curriculares, ambas provocadas pela descoberta da matemática e da pedagogia guarani. Concluiu-se que o projeto de extensão favoreceu a troca de conhecimentos entre dois grupos culturais distintos e, assim, efetivou a interculturalidade crítica.

Palavras-chave: Educação indígena. Educação matemática. Extensão universitária. Formação de professores. Interculturalidade crítica.

\section{Abstract}

\begin{abstract}
The purpose of this article is to analyze the contributions of a university extension project aimed at the continuing training of Guarani teachers for the initial formation of Mathematics teachers. The project was developed with indigenous teachers who work in two Guarani villages located in Maricá, Rio de Janeiro, and had the participation of two undergraduate students in Mathematics, extension scholarship holders. Following the principles of Decolonial Pedagogy, we sought to understand the impacts of interaction with indigenous teachers and the Guarani culture in the training of undergraduate students. This was a case study based on D'Ambrósio's ideas on ethnomathematics (1997, 1998, 2002, 2013), Tardif's ideas on teacher knowledge (2014), and Serrazina (2003), Alarcão (2001) and Nóvoa (2009) on teacher training. Throughout the project, actions were implemented that highlighted aspects of the Guarani culture. The development of the research posture of the teachers was stimulated through the analysis of their practices and the reflection on the performance of their students. Following these actions, the graduates were able to review their conception of Mathematics and Mathematics Education. Among the main results are the criticism made by them to the knowledge of training and disciplinary knowledge proposed by the university and the relativization of curricular knowledge, both provoked by the discovery of Mathematics and Guarani Pedagogy. It was concluded that the extension project favored the exchange of knowledge between two distinct cultural groups and, thus, effected critical interculturality.
\end{abstract}

Keywords: Critical interculturality. Indigenous education. Mathematical education. Teacher training. University extension.

\author{
Recebido em 19/02/2018 - Aprovado em 24/06/2018 \\ http://dx.doi.org/10.5335/rep.v25i3.8578
}

Pós-doutoramento em Educação Matemática na Pontifícia Universidade Católica de São Paulo. Professora da Universidade do Estado do Rio de Janeiro. E-mail: gabrielasb80@hotmail.com 


\section{Introdução}

O objetivo deste artigo é analisar as contribuições de um projeto de extensão universitária voltado à formação continuada de professores guarani para a formação inicial de professores de matemática. O projeto foi desenvolvido com professores indígenas que atuam em duas aldeias guarani situadas em Maricá, Rio de Janeiro, e contou com a participação de dois estudantes de licenciatura em Matemática, bolsistas de extensão. Seguindo os princípios da Pedagogia Decolonial, buscou-se compreender os impactos da interação com os professores indígenas e com a cultura guarani na formação dos estudantes de licenciatura.

O projeto de extensão abordado neste estudo intitula-se A Construção de Conceitos Matemáticos por Alunos do Curso de Educação de Jovens e Adultos Guarani, está cadastrado na Universidade do Estado do Rio de Janeiro (UERJ) desde 2013 e foi renovado em 2018. Visando a subsidiar a atuação de professores que lecionam nas escolas indígenas das duas aldeias guarani situadas em Maricá, Rio de Janeiro, a convite das lideranças destas aldeias, neste projeto investiga-se o processo de significação de conceitos constituintes dos campos de conteúdos matemáticos sugeridos para o ensino pelo Referencial Curricular Nacional para as Escolas Indígenas (RCNEI) por índios guarani. Para atingir os objetivos traçados, propõem-se três linhas de ação. A primeira consiste no levantamento dos fundamentos teóricos e epistemológicos da formação de conceitos básicos associados a números e operações numéricas, espaço e forma, grandezas e medidas e tratamento da informação; na verificação do estado da arte da pesquisa em ensino de matemática nas escolas indígenas no Brasil; nas sequências de ensino e materiais voltados para a formação de conceitos matemáticos nas escolas indígenas no Brasil; na análise dos livros didáticos de matemática utilizados nas escolas indígenas no Brasil, tendo em vista a exploração de situações-problema que favoreçam a formação e a significação dos conceitos; no tratamento dispensado à matemática e às reflexões sobre o seu ensino nos cursos de formação de professores indígenas no Brasil. A segunda corresponde à organização e à análise, à luz da Teoria dos Campos Conceituais e dos princípios da Etnomatemática, dos materiais (registros escritos, desenhos, falas, materiais manipuláveis e demais objetos) produzidos durante as aulas de matemática pelos estudantes guarani das duas aldeias de Maricá. E, finalmente, a terceira corresponde ao desenvolvimento de atividades complementares, oficinas, minicursos, orientações metodológicas e curriculares para a formação de professores indígenas. O trabalho é desenvolvido anualmente e tem como sua principal meta a assessoria às aulas de matemática das aldeias de Maricá, entretanto toda a produção fica disponível no programa Movimentos Sociais e Diferenças na Educação (Promovi- 
de) da Faculdade de Educação da Baixada Fluminense (FEBF), para ser acessada livremente pela comunidade externa à universidade.

Atuam no projeto, além da coordenadora e de professores do Departamento de Educação Matemática e de Formação de Professores da FEBF, estudantes do Programa de Pós-Graduação em Educação, Comunicação e Cultura em Periferias Urbanas e dois estudantes do curso de licenciatura em Matemática, sendo estes dois os sujeitos da pesquisa. Entende-se que as reflexões sobre um projeto que atende gratuitamente escolas indígenas, oferecendo orientações metodológicas e formação continuada para seus professores, se aproximam daquelas que se referem à extensão universitária, tema gerador deste número da Revista Espaço Pedagógico, não só pelo fato de, burocraticamente, o projeto estar cadastrado no departamento de extensão da universidade de origem, mas, principalmente, pelo caráter singularmente extensionista das ações envolvidas nele.

Como garantem Rodrigues et al., a extensão universitária teve início na Inglaterra do século XIX e "nos dias atuais surge como instrumento a ser utilizado pela universidade para a efetivação do seu compromisso social" (2013, p. 142). Nesse sentido, a extensão permite que sejam colocados a serviço da comunidade os conhecimentos produzidos no seio da universidade. Contudo, interessante nesse processo é que ambas as partes são beneficiadas (ROCHA, 2007). Por um lado, o diálogo entre a universidade e a comunidade possibilita o desenvolvimento de ações socioeducativas que favorecem a superação das condições de desigualdade e exclusão ainda existentes. Por outro lado, novos conhecimentos, produzidos no diálogo e advindos do grupo cultural para o qual o projeto se volta, permitem o avanço das pesquisas acadêmicas e o aprimoramento da formação inicial dos estudantes envolvidos nas atividades de extensão. Por isso, neste artigo, foca-se a formação inicial dos estudantes bolsistas do projeto, enfatizando as contribuições da vivência com professores indígenas nesse processo. Descarta-se a ideia da extensão centrada na universidade, tida como produtora e transmissora de conhecimentos aos demais segmentos da sociedade e, assim como Freire (1983) e Thiollent (2002), enfatiza-se a troca de saberes não hierarquizados. Corrobora-se a ideia de que "bons projetos de extensão são aqueles que geram ganhos de conhecimento e de experiência para todos os participantes, com base no ciclo relacionando ação e reflexão" (THIOLLENT, 2002, p. 7).

A fim de se apresentar mais detalhadamente o estudo, na próxima seção, fazem-se uma síntese da educação indígena no Brasil e seus pontos de aproximação com o multiculturalismo e com a Etnomatemática, que fundamentam o projeto. $\mathrm{Na}$ sequência, descrevem-se a pedagogia guarani e a concepção deste trabalho sobre formação de professores. Em seguida, apresenta-se o método usado na investigação, e realiza-se a análise dos dados coletados. 


\section{Educação indígena, multiculturalismo e Etnomatemática}

Embora nos últimos anos as etnias indígenas brasileiras tenham conquistado uma série de direitos, ainda persistem no senso comum algumas ideias equivocadas sobre os índios. Conforme Freire explica, muitas pessoas construíram

[...] uma imagem de como deve ser o índio: nu ou de tanga, no meio da floresta, de arco e flecha, tal como foi descrito por Pero Vaz de Caminha. E essa imagem foi congelada. Qualquer mudança nela provoca estranhamento. Quando o índio não se enquadra nessa imagem, vem logo a reação: "Ah! Não é mais índio". Na cabeça dessas pessoas, o "índio autêntico" é o índio de papel da carta do Caminha, não aquele índio de carne e osso que convive conosco, que está hoje no meio de nós $(2009$, p. 83).

Assim, o equívoco consiste em admitir que os índios constituem um bloco único, com a mesma cultura, compartilhando as mesmas crenças e a mesma língua; ou ainda que as culturas indígenas são congeladas ou atrasadas e primitivas, não produzem saberes, ciências, arte refinada, literatura, poesia, música, religião.

Cabe ressaltar, no entanto, que, a partir da década de 70 do século XX, diferentes organizações começaram a se estruturar com o objetivo de desfazer os equívocos citados, lutar pelos direitos indígenas e defender seus territórios. Como fruto das mobilizações sociais e políticas e das reflexões críticas que se intensificaram a partir dessa época, a Constituição federal de 1988 rompeu com a tradição integracionista de quase cinco séculos e passou a atribuir aos índios o direito à prática de suas formas culturais próprias. No que diz respeito à educação, assegurou às comunidades indígenas, no ensino fundamental regular, o uso de suas línguas maternas e processos próprios de aprendizagem. Garantiu também o ensino bilíngue (língua materna e língua portuguesa) e a proteção do Estado às manifestações culturais indígenas. Na sequência, a Lei de Diretrizes e Bases da Educação (BRASIL, 1996) reafirmou ainda mais os direitos educacionais específicos dos povos indígenas. Em linhas gerais, esta lei estabeleceu a formulação e a implantação de uma política de proteção e promoção dos direitos indígenas e o desenvolvimento de programas integrados de ensino e pesquisa para oferta de educação escolar bilíngue e intercultural a esses povos. Em síntese, traçou-se um novo perfil para a escola indígena a qual passou a ser comunitária, intercultural, bilíngue, específica e diferenciada. Passou a ser concebida e planejada como reflexo das aspirações de cada etnia indígena.

Essas conquistas vão de encontro ao processo de globalização. A globalização é um processo de homogeneização cultural que ocorre em função da difusão da ideologia capitalista (IANNI, 2000; PAGEL; GROFF, 2009). As sociedades capitalistas se caracterizam pela presença de diferentes grupos culturais hierarquizados em função do papel que desempenham e das relações que estabelecem entre si, o que 
leva a identificar grupos oprimidos e grupos opressores ou classes dominantes e classes dominadas, a que Walsh (2007) denominou "grupos subalternizados".

As exclusões social, econômica e política e o surgimento dos grupos subalternizados são consequências da opressão que a classe dominante exerce sobre as outras classes. Na tentativa de reverter este quadro, visando a lutar pelos direitos das classes subalternizadas, surgiram movimentos sociais como o multiculturalismo. O multiculturalismo é um "movimento legítimo de reivindicação dos grupos sociais para terem suas formas culturais reconhecidas e representadas na cultura nacional dominante" (SILVA, 2007, p. 85).

Para McLaren (1997), há quatro tendências de multiculturalismo: o multiculturalismo conservador; o humanista liberal; o liberal de esquerda; e o crítico e de resistência. No projeto analisado neste artigo, adota-se o multiculturalismo crítico e de resistência. Silva pontua que, de acordo com essa tendência, "os processos institucionais, econômicos, estruturais estariam na base da produção dos processos de discriminação e desigualdade baseados na diferença cultural” (2007, p. 87). Assim, não basta apenas propagar o respeito e a tolerância cultural. A ideia de tolerância pressupõe certa superioridade do grupo cultural que tolera ou respeita o outro, e "não é possível estabelecer nenhum critério transcendente pelo qual uma determinada cultura possa ser julgada superior a outra" (SILVA, 2007, p. 86). Para o multiculturalismo crítico, o essencial é promover o entendimento de que o surgimento dos grupos subalternizados é consequência da opressão que a classe dominante exerce sobre as outras classes e trazer à tona a reflexão sobre elas e as relações de poder que as fundamentam.

No caso das mais de duzentas etnias indígenas existentes hoje no Brasil (entre elas, os guarani), reconhece-se facilmente o processo de aniquilamento cultural que elas vêm sofrendo desde o século XVI e que se acelerou com a globalização contemporânea. Entretanto, também reconhece-se em suas lideranças o esforço para interrompê-lo. Esse esforço compreende a preservação dos rituais religiosos, do idioma e dos demais conhecimentos culturalmente construídos, como, por exemplo, os conhecimentos matemáticos, e se reafirma na reivindicação de uma escola indígena, multicultural e bilíngue.

Neste cenário, ganham posição central os debates sobre o currículo das escolas indígenas. Mas o currículo é entendido como alvo de problematização, como um conjunto correspondente a todas as experiências de conhecimento que são proporcionadas aos/às estudantes, e não como uma mera lista de conteúdos. Entendendo o currículo de forma mais problematizada, Silva enfatizam que é por meio dele que a escola orienta suas ações no sentido de "organizar as experiências de conhecimento de crianças e jovens com o objetivo de produzir uma determinada identidade 
individual e social" (1995, p. 184). Sendo assim, não há como não trazer, para o seio da escola e para as reflexões sobre organização curricular, as discussões provenientes do multiculturalismo crítico. Há que se levar em consideração as características culturais do meio social em que a escola se estabelece, o processo de globalização e as relações de poder que se desenvolvem a partir dele:

É via currículo que são introduzidos no interior da educação institucionalizada mecanismos de controle e regulação próprios da esfera da produção e do mercado com o objetivo de produzir resultados educacionais que se ajustem mais estreitamente às demandas $\mathrm{e}$ especificações empresariais (SILVA, 1995, p. 186).

Visto dessa maneira, concorda-se com Moreira, quando afirma que "o currículo não é um elemento inocente e neutro de transmissão desinteressada do conhecimento social. O currículo está implicado em relações de poder" (2006, p. 8). Assim, num processo de organização curricular, é preciso ter em mente quais grupos ou indivíduos são beneficiados, que identidades são privilegiadas e que grupos são subjugados. É necessário entender também como o ponto de vista, a perspectiva e a narrativa de grupos subjugados podem ser introduzidos no currículo.

A proposta atual para as escolas indígenas tem refletido essas preocupações, e, no projeto descrito, teve-se a oportunidade de vivenciá-las, sendo a principal questão relacionada à definição do que deve ser estudado. Oferecendo uma resposta, o RCNEI (BRASIL, 1998, p. 159) salienta que devem ser enfatizados conteúdos que perpassam as situações de contato entre os diferentes povos e a sociedade mais ampla. Ainda acrescenta os conceitos historicamente construídos pelas etnias que asseguram não só a preservação cultural, como também a construção da identidade dos indivíduos que compõem o grupo.

Quando restringe-se a leitura às partes que se referem à matemática, encontra-se:

A Matemática é fundamental porque permite um melhor entendimento do mundo dos brancos e ajuda na elaboração de projetos comunitários que promovam a conquista da auto sustentação das comunidades [...] o estudo da Matemática mostra que existem, na verdade, muitas Matemáticas. Isso significa reconhecer que cada sociedade tem uma maneira muito específica de entender o mundo que a cerca e formas específicas de contar e manejar quantidades. Por fim, a Matemática também é necessária para a construção de conhecimentos de outras áreas (BRASIL, 1998, p. 159).

Percebem-se as influências das ideias da Etnomatemática na elaboração do documento. Para explicar o que é a Etnomatemática, no livro Etnomatemática (1998), D’Ambrosio afirma que matemática é a união de dois radicais: “matema é uma raiz difícil, que vai na direção de explicar, de conhecer, de entender; e tica vem sem dúvida de techne, que é a mesma raiz de arte e de técnica” (1998, p. 5). Dessa 
maneira, pode-se dizer que matemática é a arte ou a técnica de explicar o mundo. A questão é que, como D’Ambrosio descreve:

[...] na tentativa de explicar o mundo em que vivem, os vários grupos culturais desenvolveram e desenvolvem processos de contagem, de medida, de classificação, de ordenação e de inferência. Isto nos leva a crer que o conhecimento matemático foi se desenvolvendo ao longo do tempo, a partir das necessidades e das características de cada cultura. Em outras palavras, assim como a língua, o artesanato, a religião e demais elementos, a Matemática é uma produção cultural (1998, p. 8).

Assim, a matemática não é uma ciência neutra, que não sofre transformações. Cada cultura produziu e, como o mundo está sempre se transformando, produz a sua matemática. Contudo, esta não é uma ideia facilmente aceita. No senso comum e numa perspectiva tradicional de ensino com relação ao conhecimento matemático, especificamente, prevalece "um paradigma positivista que compreende ser esse conhecimento neutro, livre de valor e objetivo, existindo completamente fora da consciência humana, e seu manejo se trata de descobertas de fatos estáticos e sua subsequente descrição, classificação e transmissão" (CARRIJO, 2014, p. 260).

Foi por isso que, desde o princípio do desenvolvimento do projeto, procurou-se mostrar o quanto os indivíduos conhecem e se utilizam da matemática no cotidiano, às vezes sem perceber. Teve-se a esperança não só de contribuir para que os professores indígenas refletissem sobre o ensino e a aprendizagem de conceitos matemáticos específicos, mas também de oferecer uma formação mais ampla, criando condições para que se tornassem indivíduos críticos e capazes de atuar nas mais diversas instâncias sociais. Nas oficinas realizadas com o grupo, também foi constante a preocupação com o resgate da matemática e da pedagogia guarani, seu registro e, quando possível, o reconhecimento dos elos e das rupturas entre elas e a matemática e a pedagogia presentes nas escolas não indígenas. No que concerne aos bolsistas, estudantes do curso de licenciatura em Matemática, esperou-se que a vivência no projeto impactasse sua formação profissional, de modo que apreendessem os princípios da Etnomatemática e reelaborassem seus saberes para a prática docente. A seguir, apresentam-se mais detalhadamente as ideias sobre formação de professores que fundamentam o projeto e os tipos de saberes docentes que se pretende mobilizar com os sujeitos.

\section{Decolonialidade, formação de professores e pedagogia guarani}

Como é possível perceber, no projeto de extensão A Construção de Conceitos Matemáticos por Alunos do Curso de Educação de Jovens e Adultos Guarani, tentaram-se não omitir as relações de poder que caracterizam a sociedade brasileira 
e garantir a apropriação da universidade pelos professores indígenas, público-alvo do projeto. Procurou-se contribuir para a valorização de seus saberes por meio da discussão de situações-problema que emergem de suas vivências e da legitimação das estratégias de resolução que propõem. Eles participam, por exemplo, da seleção dos temas a serem estudados, da definição dos métodos de ensino, da elaboração de recursos didáticos e de processos de avaliação. Dessa forma, aproximaram-se as práticas do projeto daquelas que se vinculam à educação intercultural na perspectiva da interculturalidade crítica (CANDAU, 2006, 2009, 2012; WALSH, 2007).

A conceituação de multiculturalismo ou de interculturalidade tem sido de grande importância para a elaboração e a implementação de políticas educacionais, orientando o desenvolvimento de propostas curriculares e de formação de professores. Segundo Tubino (2005), a interculturalidade pode se dividir em duas categorias: a funcional e a crítica. A interculturalidade funcional "é assumida como estratégia para favorecer a coesão social, assimilando os grupos socioculturais subalternizados à cultura hegemônica" (CANDAU, 2012, p. 78). Assim, ela focaliza questões socioidentitárias sem afetar a estrutura e as relações de poder vigentes. Já, na interculturalidade crítica, estas últimas são exatamente o foco.

Adotou-se no projeto e na análise dos dados obtidos, a interculturalidade crítica. Sobre ela, Walsh detalha:

a interculturalidade crítica [...] é uma construção de e a partir das pessoas que sofreram uma experiência histórica de submissão e subalternização [...] e abarca uma aliança com pessoas que também buscam construir alternativas à globalização neoliberal e à racionalidade ocidental, e que lutam tanto pela transformação social como pela criação de condições de poder, saber e ser muito diferentes (2007, p. 8).

Em outras palavras, trata-se de uma prática política que se contrapõe à hegemonia monocultural, que não só dá visibilidade aos grupos subalternizados, mas também busca transformar as instituições que têm suas práticas fundadas na lógica ocidental e na manutenção da colonialidade.

Diferentemente do colonialismo - que diz respeito às dominações política e econômica de um povo sobre outro em qualquer parte do mundo -, a colonialidade, para Walsh (2007), indica o padrão de relações que emerge no contexto da colonização europeia nas Américas e se constitui como modelo de poder moderno e permanente. Segundo Fleuri, a colonialidade atravessa praticamente todos os aspectos da vida e se configura a partir de quatro eixos entrelaçados: 
O primeiro eixo - a colonialidade do poder - refere-se ao estabelecimento de um sistema de classificação social baseado na categoria de "raça", como critério fundamental para a distribuição, dominação e exploração da população mundial no contexto capitalista-global do trabalho. O segundo eixo é a colonialidade do saber: a suposição de que a Europa se constitua como centro de produção do conhecimento descarta a viabilidade de outras racionalidades epistêmicas e de outros conhecimentos que não sejam os dos homens brancos europeus ou europeizados, induzindo a subalternizar as lógicas desenvolvidas historicamente por comunidades ancestrais. O terceiro eixo, a colonialidade do ser, é o que se exerce por meio da subalternização e desumanização dos sujeitos colonizados, à medida que o valor humano e as faculdades cognitivas dessas pessoas são desacreditados pela sua cor e pelas suas raízes ancestrais. $\mathrm{O}$ quarto eixo é o da colonialidade da natureza e da própria vida. Com base na divisão binária natureza/sociedade se nega a relação milenar entre mundos biofísicos, humanos e espirituais, descartando o mágico-espiritual-social que dá sustentação aos sistemas integrais de vida e de conhecimento dos povos ancestrais (2012, p. 10).

Assim, é preciso fazer frente à colonialidade, quando se deseja a emancipação e a preservação culturais dos povos latino-americanos. No campo da educação, a oposição à hegemonia monocultural se traduz na noção de Pedagogia Decolonial. Segundo Oliveira e Candau (2010), a Pedagogia Decolonial proposta por Walsh (2007) implica a denúncia da colonialidade e a construção de novas condições sociais, políticas, culturais e de pensamento. E, ainda, se há a pretensão de contribuir de algum modo para a construção de uma Pedagogia Decolonial, é importante conhecer as concepções que cada grupo tem de escola, o que pretende estudar e o que concebe de cada assunto pelo qual se interessa. No estudo apresentado neste artigo, procura-se identificar como as interações com os professores indígenas podem sensibilizar futuros professores de matemática para estes aspectos, tornando-os aptos a viabilizar a Pedagogia Decolonial. Assim, pode-se dizer que este estudo se enquadra na tendência de pesquisa da formação de professores.

A formação de professores é uma linha que abarca os saberes e conhecimentos docentes, as práticas de memórias e histórias, o trabalho e a profissionalização docente em contextos de educação formal (básica e superior) e não formal, na perspectiva de educação para todos (BRASIL, 1999). E as discussões atuais sobre formação de professores situam-se em um movimento, iniciado há cerca de três décadas, que busca a profissionalização do ofício de ensino. Segundo Brito e Alves (2013, p. 27), tal profissionalização pressupõe a definição da natureza dos saberes que embasam a prática docente.

Sobre o saber docente, Tardif o define como "um saber plural, formado pelo amálgama, mais ou menos coerente, de saberes oriundos da formação profissional e de saberes disciplinares, curriculares e existenciais" (2014, p. 36, grifo do autor). Os saberes da "formação profissional" são aqueles provenientes das instituições formativas. É nesses espaços que o professor tem contato com as ciências da educação e com os saberes pedagógicos. Ou seja, os saberes profissionais têm como 
finalidade as formações intelectual e científica e a constituição de um arcabouço de elementos que vão auxiliá-lo em sua prática pedagógica. Já os "saberes curriculares" referem-se aos "programas escolares (objetivos, conteúdos, métodos)" (TARDIF, 2014, p. 38) de que o professor precisa se apropriar para implementar na sua atividade educativa de forma crítica e reflexiva, enquanto os "saberes disciplinares" correspondem aos diversos campos do conhecimento à disposição da sociedade, que são oferecidos pelas instituições educacionais na forma de disciplinas, sendo a matemática um exemplo. Por fim, os "saberes existenciais" relacionam-se à prática habitual e ao conhecimento dos espaços onde estão inscritos. Segundo Tardif (2014), esses saberes são gerados da experiência e são por ela legitimados, "incorporam-se à experiência individual e coletiva sob a forma de habitus e de habilidades, de saber-fazer e saber-ser" (TARDIF, 2014, p. 39). Ainda de acordo com o autor, esses saberes

[...] não provêm das instituições de formação nem dos currículos. Estes saberes não se encontram sistematizados em doutrinas ou teorias. São saberes práticos (e não da prática: eles não se superpõem à prática para melhor conhecê-la, mas se integram a ela e dela são partes constituintes enquanto prática docente) e formam um conjunto de representações a partir das quais os professores interpretam, compreendem e orientam sua profissão e sua prática cotidiana em todas as suas dimensões. Eles constituem, por assim dizer, a cultura docente em ação (TARDIF, 2014, p. 48-49).

Identificados os tipos de saber, é importante observar que Tardif (2014) não estabelece nenhuma espécie de hierarquização entre eles, uma vez que todos eles são contributos essenciais que compõem a prática do professor. Contudo, um dado relevante que Tardif (2014) verificou em suas pesquisas diz respeito às relações que os professores mantêm com esses saberes: eles, em geral, se enquadram na condição de portadores ou transmissores desses saberes, e não de produtores.

Diante desse quadro, infere-se que ele se deve especialmente às crenças e concepções que os professores construíram ao longo de suas vivências, quer profissionais, quer como estudantes, desde a educação básica. Reconhece-se que "as crenças e concepções são uma espécie de lente ou de filtro, que os professores utilizam para interpretar seu processo formativo. Além disso, elas dispõem e dirigem as experiências docentes" (BARRANTES; BLANCO, 2004 apud BRITO; ALVES, 2013, p. 29).

Há, então, forte conexão entre as crenças e concepções e a prática, de modo que as crenças e concepções conduzem as ações educativas e são validadas pela prática, assim como a reflexão sobre a prática pode engendrar novas concepções ou reelaborar as existentes. Nesse sentido, restringindo-se ao caso dos professores que ensinam matemática, Nacarato, Mengali e Passos (2015) ressaltam que o conhecimento do professor, suas crenças e concepções sobre a matemática e seu nível de confiança para desenvolver o ensino/aprendizagem dessa disciplina se ma- 
nifestam em sala de aula. Segundo as autoras, a postura de transmissor em vez de produtor de saberes se deve à metodologia de ensino tradicional que os professores experienciaram enquanto alunos. Como mencionado anteriormente, os professores indígenas já haviam passado pela escola não indígena na educação básica e foi constatado já nos primeiros encontros que esta passagem não os levou à postura de transmissores, pois, como é exposto adiante, em suas práticas, há marcadamente a presença da pedagogia guarani. No entanto, tal experiência afetou diretamente sua confiança para o ensino de matemática.

Nacarato, Mengali e Passos (2015) orientam que as instituições formativas devem elaborar estratégias para desconstruir esses saberes que foram adquiridos durante a escolarização. Nessa direção, Brito e Alves (2013) consideram que, quando os professores refletem sobre suas crenças e concepções relativas à matemática, ao ensino e à aprendizagem, podem ser levados a modificá-las de modo a construir saberes docentes indispensáveis à sua futura prática docente. Mas como iniciar esse processo de reflexão?

Nóvoa (2009) entende que a profissão docente é muito mais que a competência de saber transmitir um determinado conhecimento, reconhece a importância dos trabalhos de investigação científica desenvolvidos pelos especialistas educacionais e de todo arcabouço teórico ou metodológico, dos pontos de vista científico e pedagógico, para a constituição do ser professor. Porém, defende que os professores mais experientes deveriam ocupar uma posição central no processo formativo dos mais jovens, e que é necessário considerar o conhecimento profissional docente, que se constrói na reflexão do que se faz no cotidiano da profissão. Segundo esse autor, a construção da identidade docente passa pelo entrelaçamento entre as dimensões pessoal e profissional, num movimento de produção de um conhecimento pessoal dentro do conhecimento profissional. Sintetizando toda essa argumentação, Nóvoa conclui:

No essencial, advogo uma formação de professores construída dentro da profissão, isto é, baseada numa combinação complexa de contributos científicos, pedagógicos e técnicos, mas que tem como âncora os próprios professores, sobretudo os professores mais experientes e reconhecidos (2009, p. 216).

Corroborando essas ideias, Barth (1993) destaca, ainda, a valorização da formação e da reflexão teórico-epistemológica do professor, ao afirmar que é preciso conhecer as teorias que estão implícitas na prática dos professores e, ao mesmo tempo, propiciar condições para que estes avancem no sentido de modificar suas concepções, posturas, crenças e ações de prática educativa. Já Pimenta (2002) acrescenta que a consideração da reflexão sobre a prática está pautada em uma análise de implicações sociais, econômicas e políticas que permeiam o ato de en- 
sinar e questiona as condições concretas que o professor tem para refletir. Para a autora, considerar essas questões é importante para não incorrer no erro de achar que a prática isolada, por si só, é suficiente para a construção do saber docente, é essencial também que o ato de reflexão não ocasione um individualismo, acreditando-se que se resolvem todos os problemas da prática ao refletir sobre esta. Em outras palavras, Tardif encerra a mesma ideia:

[...] o conhecimento da matéria ensinada e o conhecimento pedagógico (que se refere a um só tempo ao conhecimento dos alunos, à organização das atividades de ensino e aprendizagem e à gestão da classe) certamente são conhecimentos importantes, mas estão longe de abranger todos os saberes dos professores no trabalho (2014, p. 260).

À luz dessas ideias, vislumbra-se que, ao longo de sua formação, quer inicial, quer continuada, o professor que vai ensinar matemática deve se tornar apto a planejar suas aulas, escolhendo os recursos didáticos mais adequados, valorizando aspectos culturais de seus alunos nas aulas e na organização curricular e reconhecendo as etapas da aprendizagem que eles estejam vivenciando, aspectos que se procuram privilegiar no curso de extensão apresentado. Entende-se que não se pretende formar cientistas sociais, nem psicólogos, nem matemáticos, mas indivíduos capazes de pesquisar sobre sua prática, integrando essas três áreas do conhecimento e promovendo uma aprendizagem significativa da matemática. Logo, vamos ao encontro de Alarcão, quando afirma que é inconcebível:

[...] um professor que não se questione sobre as razões subjacentes às suas decisões educativas, que não se questione perante o insucesso de alguns alunos, que não faça dos seus planos de aulas meras hipóteses de trabalho a confirmar ou infirmar no laboratório que é a sala de aula, que não leia criticamente os manuais ou as propostas didáticas que lhe são feitas, que não se questione sobre as funções da escola e sobre elas estão a ser realizadas (2001, p. 5).

Como Alarcão (2001), defende-se que, para que um professor seja bem-sucedido na sua profissão, ele também seja um pesquisador, um investigador de suas práticas. Trazendo essa reflexão para a formação de professores que ensinam matemática, Serrazina sugere que os cursos de formação devem criar condições para que seu egresso seja:

- um facilitador da aprendizagem significativa dos alunos, gerando conhecimento escolar, uma vez que são os alunos que aprendem e o professor deve ser capaz de criar as melhores condições para que isso aconteça;

- um investigador dos processos de ensino/aprendizagem que acontecem na sua turma, gerando assim conhecimento profissional;

- um constante construtor do currículo, conduzindo experiências com os seus alunos, refletindo sobre elas e reformulando-as;

- um gerador de conhecimento didático significativo ao investigar sobre os processos de desenvolvimento do currículo (2003, p. 69). 
Tendo em vista tais itens, foi inevitável questionar: destes, quais perpassam as práticas dos professores guarani? O que as pesquisas científicas sinalizam sobre os professores guarani?

Encontraram-se respostas nas pesquisas de Nobre (2009) e Faustino (2012). Este, relatando sua experiência com os guarani do Norte do Paraná, ressalta que:

Tradicionalmente, a educação Guarani se dá por múltiplas linguagens contidas nas vivências do grupo familiar. A observação, os gestos, a participação nas atividades de trabalho, religiosas e de lazer representam, para a criança, a inserção em um rico e complexo mundo cultural. É a educação pelo olhar, ouvir, participar, repetir, pensar, criar e recriar (FAUSTINO, 2012, p. 257).

Essa perspectiva reforça as ideias de Nobre (2009) sobre as características da pedagogia indígena guarani. Assistindo às aulas de professores guarani nas aldeias de Sapukai, em Angra dos Reis, e de Paraty-Mirim, em Paraty, identificaram-se onze elementos que caracterizam a pedagogia guarani. São eles: 1) autonomia, liberdade e descontração dos alunos; 2) forte participação dos alunos; 3) grande curiosidade e observação; 4) o guarani como língua de instrução; 5) forte presença da oralidade, com certo desapego à escrita;6) necessidade de preservação da cultura; 7) presença de ritual nas aulas; 8) ocorrência de imitação; 9) ocorrência de repetição nas atividades; 10) grande respeito mútuo nas relações; e 11) grande ocorrência de desenho nas atividades.

A identificação desses elementos e sua confirmação por meio de entrevista semiestruturada com os professores indígenas foram fundamentais para que se definissem as ações do projeto de extensão. A utilização de uma pedagogia distinta daquela que os professores conheceram quando frequentaram uma escola indígena e realizam em suas práticas poderia lhes causar estranhamento e talvez um afastamento do projeto. Além disso, esses elementos vão ao encontro das orientações de D’Ambrosio (1998; 2002) para a criação de um programa de ensino fundamentado nos princípios da Etnomatemática. É por meio da participação ativa e do uso dos sistemas simbólicos e representações que lhes são familiares que os alunos trazem para a escola as questões e os conhecimentos produzidos no seu meio social. Tais aspectos, segundo o autor, devem ser o foco de trabalho do professor. Os conhecimentos que os alunos produziram previamente ou produzem fora da escola, ao estarem presentes nela, além de evidenciarem as aplicações do que está sendo estudado, permitem-lhes perceber conexões entre conceitos e, mesmo, entre áreas do conhecimento humano. Na próxima seção, faz-se uma descrição mais detalhada das características do projeto e do método de pesquisa. 


\section{Método}

Esta pesquisa é qualitativa. Para Goldenberg (1999), nesse tipo de pesquisa, o investigador não se preocupa em estabelecer quantificações do grupo investigado, mas o entendimento aprofundado da realidade de cada indivíduo, grupo, organização ou instituição, suas trajetórias e subjetividades. Segundo a autora, "os dados qualitativos consistem em descrições detalhadas de situações com o objetivo de compreender os indivíduos em seus próprios termos" (GOLDENBERG, 1999, p. 53).

Entre tantos modelos de pesquisa qualitativa, escolheu-se o estudo de caso. Gil (2008) afirma que ele consiste no estudo profundo e exaustivo de um ou poucos objetos, de maneira que permita seu amplo e detalhado conhecimento. Dessa forma, buscando descrever e analisar as contribuições das vivências em um projeto de extensão que subsidia a atuação de professores indígenas para a formação profissional de dois futuros professores de matemática, procurou-se, à luz da análise do processo de formação continuada dos professores indígenas (BARBOSA, 2018), interpretar os saberes (TARDIF, 2014) construídos pelos licenciandos. Para isso, acompanharam-se as participações de cada um no projeto ao longo de 2016. É importante mencionar que, no primeiro semestre de 2016, ambos cursavam o sexto período de um curso de licenciatura composto por oito períodos.

Reforçando as escolhas metodológicas adotadas, Lüdke e André trazem uma caracterização para a pesquisa qualitativa em educação:

[...] envolve a obtenção de dados descritivos, obtidos no contato direto do pesquisador com a situação estudada, enfatiza mais o processo do que o produto e se preocupa em retratar a perspectiva dos participantes (2014, p. 14).

Além disso, Lüdke e André (2014), bem como Araújo e Borba (2013), apontam que, na pesquisa qualitativa, a fonte direta de dados é o ambiente natural sob investigação. Considera-se importante a apreensão do significado atribuído pelos participantes à sua realidade e a suas ações, e a indução é o método empregado na análise dos dados. Indo ao encontro dessas ideias, acompanhou-se cada uma das etapas do projeto, realizando entrevistas semiestruturadas com os sujeitos e observações que ficaram registradas no diário de bordo. Em síntese, o projeto se delineou nas seguintes etapas: 
Quadro 1 - Etapas do projeto de extensão

\begin{tabular}{|c|c|}
\hline Mês (Etapa) & Ações \\
\hline Fevereiro & $\begin{array}{l}\text { Estudo da teoria Etnomatemática e de pesquisas em educação matemática que } \\
\text { se fundamentaram nesta teoria. }\end{array}$ \\
\hline Março & $\begin{array}{l}\text { Revisão dos dados coletados no projeto e organização dos materiais didáticos } \\
\text { produzidos em } 2015 \text {. }\end{array}$ \\
\hline Abril & $\begin{array}{l}\text { Integração dos membros do projeto com os professores indígenas por meio de } \\
\text { redes sociais e de grupos de WhatsApp. }\end{array}$ \\
\hline Maio & $\begin{array}{l}\text { Visita à aldeia para acompanhamento das aulas; entrevista com os professores } \\
\text { indígenas; produção de material didático para o bloco número e sistemas de } \\
\text { numeração do RCNEI. }\end{array}$ \\
\hline Junho & $\begin{array}{l}\text { Visita à aldeia para acompanhamento das aulas; entrevista com os professores } \\
\text { indígenas; produção de material didático para o bloco número e sistemas de } \\
\text { numeração do RCNEl; oferta de curso de extensão com carga horária de } 45 \mathrm{~h} \text {. }\end{array}$ \\
\hline Julho & $\begin{array}{l}\text { Visita à aldeia para acompanhamento das aulas; entrevista com os professores } \\
\text { indígenas; produção de material didático para o bloco grandezas e medidas do } \\
\text { RCNEl; continuação da oferta do curso de extensão com carga horária de } 45 \mathrm{~h} \text {. }\end{array}$ \\
\hline Agosto & $\begin{array}{l}\text { Visita à aldeia para acompanhamento das aulas; entrevista com os professores } \\
\text { indígenas; produção de material didático para o bloco grandezas e medidas do } \\
\text { RCNEl; redação de artigos científicos. }\end{array}$ \\
\hline Setembro & $\begin{array}{l}\text { Visita à aldeia para acompanhamento das aulas; entrevista com os professores } \\
\text { indígenas; produção de material didático para o bloco espaço e forma do } \\
\text { RCNEl; redação de artigos científicos. }\end{array}$ \\
\hline Outubro & $\begin{array}{l}\text { Visita à aldeia para acompanhamento das aulas; entrevista com os professores } \\
\text { indígenas; produção de material didático para o bloco tratamento da informação; } \\
\text { redação de artigos científicos. }\end{array}$ \\
\hline Novembro & Oferta de um curso de extensão com carga horária de $20 \mathrm{~h}$. \\
\hline Dezembro & Avaliação do projeto com as comunidades indígenas parceiras. \\
\hline
\end{tabular}

Fonte: dados do projeto.

Complementando, D'Ambrósio (2013) entende que a pesquisa qualitativa é uma forma de inovação. Segundo esse autor, ela "lida e dá atenção às pessoas e às suas ideias, procura dar sentido a discursos e narrativas que estariam silenciosos. E a análise dos resultados permitirá propor os próximos passos" (D’AMBRÓSIO, 2013, p. 21), o que, nesta pesquisa, não foi diferente. Nessa direção, cabe mencionar apenas que, para desvelar tais discursos e narrativas, se orientou a análise de dados para o levantamento das crenças dos sujeitos sobre o que vem a ser a matemática e o seu ensino e de seus conhecimentos e entendimentos sobre os conceitos matemáticos e recursos didáticos para o ensino desses conceitos. Devido à diversidade de dados coletados, no presente artigo, analisaram-se os dados referentes a números e sistemas de numeração.

Por fim, Araújo e Borba (2013) salientam que, numa pesquisa qualitativa em educação matemática, é importante que haja uma consonância entre a metodo- 
logia empregada e as concepções de conhecimento, de matemática e de educação matemática do pesquisador. Nesse sentido, destacam também que os resultados da pesquisa são diretamente influenciados por essas concepções. Cabe ressaltar, então, que se concorda com os teóricos apresentados anteriormente, tanto no que concerne à educação indígena quanto no que diz respeito à formação de professores que ensinam matemática.

\section{Contribuições para a formação inicial dos futuros professores de matemática}

Como apresentou-se anteriormente, com base em estudos sobre formação inicial de professores, Nóvoa (2009) afirma que a formação docente deve ocorrer ao lado da reflexão do que se faz no dia a dia da profissão e destaca a posição central que os professores mais experientes devem ocupar nesse processo formativo. A tais temáticas, Nóvoa (2009) e Tardif (2014) incorporam a categorização dos saberes fundamentais à prática. Para efetuar a análise de dados, consideram-se as experiências relatadas pelos professores indígenas e os saberes construídos pelos licenciandos ao participarem das reflexões sobre essas experiências.

Os trabalhos envolvendo cada bloco de conteúdos tinham início na reflexão dos professores acerca de suas concepções sobre os conceitos matemáticos envolvidos e os recursos didáticos e planejamentos usados para lecionar e solicitados para levar aos encontros. Na Figura 1, apresenta-se a imagem do recurso didático utilizado por um dos professores para o ensino de conceitos pertencentes ao bloco números e sistemas de numeração:

Figura 1 - Recurso didático para o ensino de números

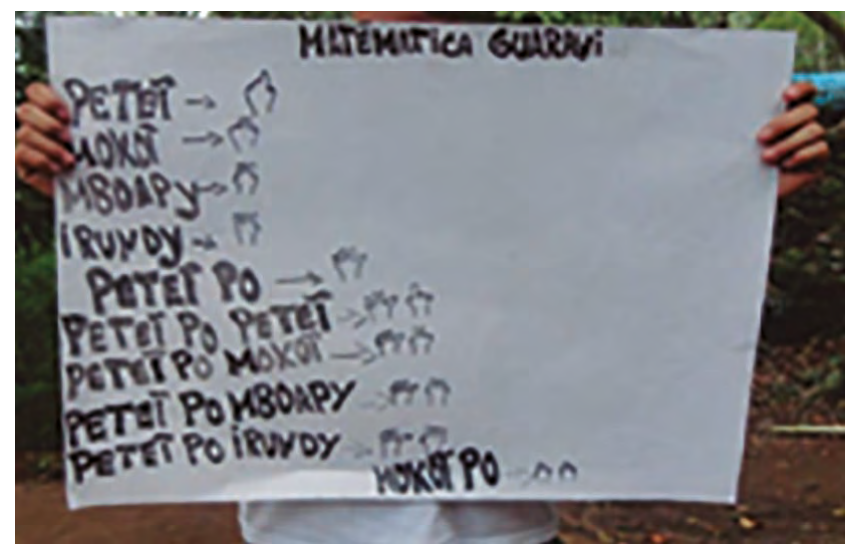

Fonte: Barbosa (2018). 
Como pode ser observado, o recurso didático utilizado por este professor é o cartaz. Segundo Barbosa (2018), isso ocorre devido não só à ausência de lousa na escola, mas também para que os professores possam aprofundar suas explicações. $\mathrm{O}$ cartaz contém palavras-número e desenhos de mãos indicando as respectivas quantidades, evidenciando um aspecto marcante da pedagogia guarani: o uso de desenhos nas aulas. Ao acompanharem as explicações dos professores sobre a importância que atribuíam aos desenhos, os licenciandos tiveram oportunidade de rever saberes vivenciais sobre o uso das imagens nas aulas e construir novos saberes. Sobre seus saberes vivenciais, o licenciando A comentou: "Quando eu era criança, os desenhos eram usados mais para enfeitar as folhinhas de atividades e as páginas dos livros. Depois, quando fui crescendo, os professores pararam de colocar desenhos". E o licenciando B acrescentou: "Pelo que estes professores mostraram, os desenhos podem ser relacionados à fala e à escrita e fica mais fácil para os alunos aprenderem". Percebe-se que o primeiro detectou o uso meramente decorativo das imagens, e o segundo demonstrou a compreensão de que as imagens podem ser utilizadas para outros fins. Para B, elas podem representar os conceitos que estão sendo estudados, e a comparação entre as diferentes representações favorece a aprendizagem (VERGNAUD, 1990).

Estudando a construção de saberes por parte dos professores indígenas deste projeto, Barbosa (2018) destaca que a preocupação com os usos sociais do número esteve presente em cada vivência relacionada ao bloco números e sistemas de numeração. Segundo estes professores, é preciso conhecer os números para comparar salários, preços, quantidades e medidas em geral. Na Figura 2, apresenta-se um exemplo desse ponto de vista numa imagem de aula fornecida por um dos professores. Trata-se de uma atividade que ele costuma realizar com sua turma em todos os meses do ano, independentemente do conteúdo matemático que esteja ensinando:

Figura 2 - Trabalho com encartes do supermercado próximo à aldeia

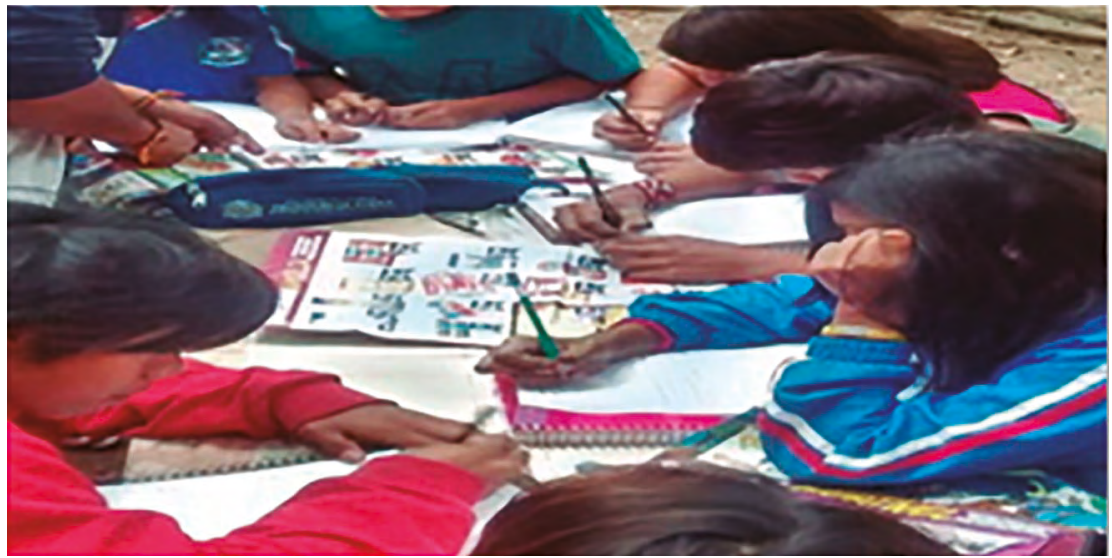

Fonte: Barbosa (2018). 
Nas palavras de Barbosa:

[...] nesta atividade o professor leva para o grupo encartes do supermercado próximo à aldeia e pede para que cada um faça sua lista de compras, compare preços e estime ou utilize uma calculadora para calcular o valor de sua lista. Embora muitos preços constantes na lista sejam números racionais que não são naturais, os professores avaliam que é necessário apresentar, ainda que informalmente, outros conjuntos numéricos para as crianças desde seus primeiros momentos na escola (2018, p. 231).

A reflexão sobre esta atividade criou condições para que os licenciandos, futuros professores, construíssem novos saberes curriculares. Em entrevista, ambos demonstraram uma concepção tradicional do ensino dos conjuntos numéricos. Nesta concepção, os conjuntos numéricos são apresentados de modo sequencial, ou seja, o conjunto dos números racionais só é apresentado depois de concluído o estudo dos números naturais. No entanto, a proposta dos professores indígenas é outra - trata-se da abordagem concomitante dos dois conjuntos -, e os argumentos que utilizam para defendê-la também convenceram os licenciandos das potencialidades didáticas desta estratégia. Os relatos das experiências satisfatórias com os alunos que eles trouxeram foram fundamentais no processo de convencimento. Foi possível uma análise crítica do currículo tradicional, e admitiu-se a possibilidade de novas organizações curriculares.

É importante observar que, conforme a discussão sobre os usos do número se aprofundava, aprofundavam-se também reflexões sobre conceitos matemáticos e seus respectivos ensinos, favorecendo a construção de saberes disciplinares e de formação profissional. Por exemplo, as situações que favoreceram a comparação de números suscitaram reflexões sobre os conceitos de antecessor e sucessor e sobre a reta numérica, vista simultaneamente como conceito e recurso de ensino. Ainda que não usassem o vocabulário formal da educação matemática, ao exporem suas preocupações e práticas sobre o ensino dos conceitos de antecessor e sucessor de um número natural, os professores indígenas criaram condições para que os licenciandos reconhecessem os dois esquemas fundamentais na construção do conceito de número - a ordenação e a inclusão hierárquica (PIAGET; SKEMINSKA, 1975) - e permitiram-lhes compreender que as operações de adição e subtração são necessárias nesse processo. De posse desses novos saberes, os futuros professores questionaram a organização curricular do curso de licenciatura que frequentam. Nas palavras de A: "A gente estuda tanta coisa na faculdade, tanta coisa tão difícil que a gente nunca vai ensinar, e essas coisas que estamos vendo aqui não entram em nenhuma disciplina". De fato, as ideias associadas à construção do conceito de número compõem saberes de formação profissional fundamentais para um professor de matemática e deveriam constar em ementas das disciplinas específicas do curso (CARVALHO, 2014). 
Nas atividades do projeto com os professores indígenas, procurou-se identificar com eles aspectos elementares do conceito de número que são estruturantes para a compreensão. Nesse sentido, Barbosa (2018) destaca, por exemplo, questionamentos sobre as estratégias de contagem, sobre o uso das palavras-número em guarani e em português e sobre a representação dos números com algarismos hindu-arábicos. Um episódio ilustrativo envolveu a reflexão sobre o que as crianças costumam contar e o modo como realizam suas contagens. Os professores indígenas, pesquisando sobre suas práticas, atitude fundamental para o exercício da profissão segundo Serrazina (2003), reconheceram que alguns de seus alunos, frente a uma situação de contagem, costumam se perder, contando o mesmo elemento mais de uma vez ou esquecendo-se de contar algum elemento. A discussão sobre esses equívocos ateve-se principalmente ao conceito de correspondência biunívoca e sua importância na construção do conceito de número. Segundo Barbosa (2018), descrevendo suas práticas, os professores indígenas enfatizaram para os licenciandos que, no ensino dos números e da contagem, além das palavras número em português e em guarani e da associação de cada número à sua respectiva quantidade, é preciso criar condições para que as crianças coordenem gestos (o dedo apontado para cada semente que está sendo contada) e fala no enunciar da sequência numérica, quer em português quer em guarani (PIAGET; SKEMINSKA, 1975). Neste episódio, dois aspectos chamaram a atenção dos licenciandos. $\mathrm{O}$ primeiro diz respeito mais uma vez aos conhecimentos sobre o processo de construção do conceito de número, saberes de formação profissional negligenciados no curso de licenciatura. $\mathrm{O}$ segundo se associa à postura investigativa dos professores indígenas e ao papel central que os alunos ocupam nas práticas de sala de aula, outros dois elementos característicos da pedagogia guarani. Com saberes vivenciais construídos a partir de experiências de ensino tradicionais, em que os estudantes são vistos como meros receptores de conteúdos, os licenciandos surpreenderam-se, por exemplo, com a importância dos pequenos gestos dos estudantes para a aprendizagem e com a atenção que lhes é dada pelos professores. Embora inicialmente esses elementos possam ter causado estranhamento, A e B concordaram com as práticas e preocupações dos professores indígenas, demonstrando a reelaboração de seus saberes vivenciais.

Na sequência, Barbosa (2018) assegura que a discussão sobre agrupamentos e seus desdobramentos, voltando as atenções tanto dos professores indígenas quanto dos futuros professores para as palavras-número em português e em guarani, conduziu a uma discussão final sobre uma possível base de contagem para o sistema de numeração guarani. Por meio de uma leitura atenta dessas palavras, os professores perceberam facilmente que há palavras absolutamente distintas para os números até 5 , e que a palavra pó, que em guarani significa mão, também no- 
meia este número. A partir de 6, as palavras usadas para designar os números são combinações das palavras usadas para designar os números até 5 . Por exemplo, os números $6,7,8,9$ e 10 são designados por palavras que, traduzidas com rigor, significam, respectivamente, uma mão e um, uma mão e dois, uma mão e três, uma mão e quatro e duas mãos. É evidente que, para uma afirmação categórica de que o sistema de numeração guarani é de base 5, é necessário um estudo mais aprofundado da história e dos hábitos desta cultura. Porém, relevante foi a identificação de conceitos e representações próprios da matemática guarani, o que permitiu uma reflexão mais ampla sobre os princípios da Etnomatemática (D'AMBRÓSIO, 1998). Entre os saberes vivenciais dos futuros professores estavam as concepções de que a matemática é universal e um conhecimento neutro, isento das influências e marcas culturais de cada grupo (CARRIJO, 2014). Romper com essas noções não é uma tarefa simples, uma vez que elas não só se constroem nas vivências escolares, mas também fazem parte do senso comum. O convívio com os professores indígenas e os vários exemplos de conceitos matemáticos específicos da cultura guarani trazidos por eles impactaram as concepções dos licenciandos sobre o que vem a ser a matemática e, consequentemente, o seu ensino (NACARATO; MENGALI; PASSOS, 2015), admitindo-os, então, como elementos culturais. A nova concepção, por sua vez, implicou novas críticas ao curso de licenciatura em Matemática e a construção de novos saberes curriculares. Os licenciandos questionaram, por exemplo, a ausência de um estudo mais aprofundado sobre a Etnomatemática no seu curso de licenciatura e debruçaram-se sobre o RCNEI, documento oficial que aponta diretrizes para a organização curricular das escolas indígenas. Por fim, estabeleceram comparações entre o RCNEI e os Parâmetros Curriculares e a Base Nacional Comum Curricular. Nesse exercício, avançavam na construção de saberes curriculares.

Ao conhecerem a matemática guarani, os futuros professores questionaram se o sistema de numeração guarani ainda deveria ser ensinado na escola indígena. Em resposta, os professores indígenas explicaram que o sistema de numeração guarani não tem palavras para nomear muitos números dos quais os índios precisam para lidar na sociedade envolvente, e, em muitos casos, as crianças misturam os dois sistemas (o guarani e o decimal) até passarem a adotar somente o decimal. Porém, explicaram também que o ensino deste sistema coloca em evidência na escola a existência de uma matemática guarani e pode ser visto como um símbolo da luta dos guarani pela preservação da sua cultura e da sua história, ou seja, uma luta contra o abafamento cultural tão bem sinalizado por Walsh (2007). Esta discussão possibilitou ainda uma reflexão mais ampla sobre a escola não indígena. Reconhecendo a existência das matemáticas dos vários grupos culturais que fre- 
quentam a escola regular, os licenciandos constataram o processo de subalternização a que estes grupos são submetidos. Assim, foram compreendendo que ensinar, isto é, ser professor, é uma atitude política. Por meio de suas escolhas curriculares e práticas educativas, o professor pode dar visibilidade a grupos subalternizados e instrumentalizá-los os para o convívio com outros grupos na busca por equidade social (OLIVEIRA; CANDAU, 2010).

\section{Considerações finais}

Neste artigo, procurou-se analisar as contribuições da participação em um projeto de extensão universitária voltado à formação continuada de professores indígenas para a formação inicial de professores de matemática. Assim, acompanhou-se durante um ano a atuação de dois estudantes de licenciatura em Matemática, bolsistas de um projeto de extensão que oferece formação continuada para professores indígenas de duas aldeias do município de Maricá, Rio de Janeiro. Tratou-se de um estudo de caso no qual se investigaram os saberes docentes construídos pelos licenciandos a partir da vivência e da troca de experiências com os professores indígenas.

As reflexões sobre o ensino dos conceitos associados a número e contagem levaram os licenciandos a questionar os saberes de formação profissional e os saberes disciplinares que vêm construindo na universidade. Eles destacaram a ausência de disciplinas, seminários ou qualquer outra prática que promova a construção de saberes mais aprofundados, associados à didática da matemática e, mais especificamente, à compreensão do processo de construção do número, conceito central na matemática.

Cabe mencionar também que os futuros professores tiveram oportunidade de conhecer aspectos da pedagogia guarani, como a utilização de desenhos nas aulas e o papel central que o aluno ocupa no processo de ensino aprendizagem. Esses elementos impactaram os saberes vivenciais que vinham construindo ao longo de seus anos de escolaridade tanto na educação básica quanto na superior e, associados ao reconhecimento da postura investigativa dos professores indígenas, fizeram com que reelaborassem seus saberes na direção de um ensino menos tradicional, no qual o aluno é o ator principal.

Em particular, a análise do sistema de numeração guarani e a reflexão sobre a pertinência de seu ensino na escola indígena contribuíram significativamente para a formação inicial dos bolsistas. Conhecendo exemplos da matemática guarani, eles puderam compreender os princípios da Etnomatemática e conceber o conhecimento matemático como um constructo cultural. A construção de uma nova con- 
cepção para a matemática, por sua vez, conduziu-os ao reconhecimento das funções políticas que perpassam as ações de um professor.

Por fim, tendo em vista as contribuições do projeto estudado para a formação inicial dos bolsistas e reconhecendo que essas contribuições se devem principalmente às interações com os professores indígenas, pode-se inferir que todos os envolvidos tiveram oportunidade de aprendizagem durante a realização do projeto. Como Barbosa (2018) bem explica, neste projeto, os professores indígenas puderam construir saberes associados aos conceitos matemáticos e à didática da matemática. No entanto, ressalta-se que esta via de aprendizagem teve mão dupla: os professores indígenas, revelando aspectos da matemática e da pedagogia guarani, também contribuíram para que os demais indivíduos envolvidos no projeto construíssem novos saberes docentes. Assim, pode-se afirmar que no projeto não houve hierarquização de saberes. Concretizou-se uma extensão universitária nos moldes propostos por Freire (1983) e Thiollent (2002).

\section{Referências}

ARAÚJO, J. L.; BORBA, M. C. Construindo pesquisas coletivamente em Educação Matemática. In: BORBA, M. C.; ARAÚJO, J. L. (Org.). Pesquisa Qualitativa em Educação Matemática. Belo Horizonte: Autêntica, 2013. p. 31-51.

ALARCÃO, I. Professor-investigador: que sentido? Que formação? In: CAMPOS, B. P. (Org.). Formação profissional de professores no ensino superior. Porto: Porto Editora 2001. p. 21-31. (v. 1).

BARBOSA, G. S. Formação continuada de professores guarani: um estudo de conceito sobre números naturais. Zetetiké, Campinas, SP, v. 26, n. 1, p. 221-239, jan./abr. 2018.

BARTH, B. O saber em construção - para uma pedagogia da compreensão. Lisboa, Portugal: Instituto Piaget, 1993. (Coleção Horizontes Pedagógicos).

BRASIL. Ministério da Educação. Referencial Curricular Nacional para as Escolas Indígenas. Brasília: MEC, 1998.

MEC. SEF. Referenciais para formação de professores. Brasília: SEF, 1999.

Lei $n^{\circ}$ 9.394, de 20 de dezembro de 1996. Estabelece as Diretrizes e Bases da Educação Nacional. Diário Oficial da União, Poder Legislativo, Brasília, DF, 23 dez 1996. p. 27833. Disponível em: <http://www.planalto.gov.br/ccivil_03/leis/I9394.htm>. Acesso em: 18 jun. 2001.

BRITO, A. J.; ALVES, F. T. O. Profissionalização e saberes docentes: análise de uma experiência em formação inicial de professores de Matemática. In: NACARATO, A. M.; PAIVA, M. A. V. (Org.). A formação do professor que ensina Matemática: perspectivas e pesquisas. 3. ed. Belo Horizonte: Autêntica, 2013. p. 27-42.

CANDAU, V. M.(Org.). Educação intercultural e cotidiano escolar. Rio de Janeiro: 7 Letras, 2006. 
. Educação intercultural na América Latina: entre concepções, tensões e propostas. Rio de Janeiro: 7 Letras, 2009.

Diferenças culturais, interculturalidade e educação em direitos humanos. Educação \& Sociedade, Campinas, v. 33, n. 118, p. 235-250, 2012.

CARRIJO, M. H. S. O resgate do poder social da matemática a partir da educação matemática crítica: uma possibilidade na formação para a cidadania. Revista Paranaense de Educação Matemática, Campo Mourão, v. 3, n. 5, p. 248-270, 2014.

CARVALHO, M. (Org.). Matemática e Educação Infantil: investigações e possibilidades de práticas pedagógicas. 2. ed. Petrópolis, RJ: Vozes, 2014. p. 145-162.

D’AMBRÓSIO, U. Transdisciplinaridade. São Paulo: Palas Athenas, 1997.

. Etnomatemática: arte ou técnica de explicar ou conhecer. 5 ed. São Paulo: Ática, 1998. 2002 .

. Etnomatemática. Elo entre as tradições e a modernidade. 2 ed. Belo Horizonte: Autêntica,

Prefácio. In: BORBA, M. C.; ARAÚJO, J. L. (Org.). Pesquisa Qualitativa em Educação Matemática. Belo Horizonte: Autêntica, 2013. p. 11-22.

FAUSTINO, R. C. Educação e religião guarani no Paraná: estudo a partir do ritual Nimongarai. Práxis Educativa, Ponta Grossa, v. 7, p. 239-263, 2012.

FLEURI, R. M. Educação intercultural: decolonializar o poder e o saber, o ser e o viver. Visão Global, Joaçaba, v. 15, n. 1-2, p. 7-22, jan./dez 2012. Disponível em: <unoesc.edu.br/index.php/ visaoglobal/article/viewFile/3408/1507>. Acesso em: 22 jul. 2015.

FREIRE, P. Extensão ou comunicação? 7. ed. Rio de Janeiro: Paz e Terra, 1983.

FREIRE, J. R. B. Cinco idéias equivocadas sobre o índio. Revista do Centro de Estudos do Comportamento Humano (CENESCH), v. 1, 2002, p. 17-33, 2009.

GIL, A. C. Como elaborar projetos de pesquisa. 4. ed. São Paulo: Atlas, 2008.

GOLDENBERG, M. A arte de pesquisar: como fazer pesquisa qualitativa em Ciências Sociais. 10. ed. Rio de Janeiro: Record, 1999.

IANNI, O. O discurso filosófico da modernidade: doze lições. São Paulo: Martins Fontes, 2000.

LÜDKE, M.; ANDRÉ, M. Pesquisa em Educação: abordagens qualitativas. São Paulo: Editora EPU, 2014.

MCLAREN, P. A vida nas escolas. Uma introdução à pedagogia crítica nos fundamentos da educação. Porto Alegre: Artes Médicas, 1997.

MOREIRA, A. F. B. Sociologia e teoria crítica do currículo: uma introdução. In: MOREIRA, A. F. B.; SILVA, T. T. (Org.). Currículo, cultura e sociedade. 8. ed. São Paulo: Cortez, 2006.

NACARATO, A. M.; MENGALI, B. L. S.; PASSOS, C. L. B. A Matemática nos anos iniciais do ensino fundamental: tecendo fios do ensinar e do aprender. 2. ed. Belo Horizonte: Autêntica, 2015.

NOBRE, D. B. Uma pedagogia indígena guarani na escola, pra quê? Rio de Janeiro: Curt Nimuendaju, 2009. 
NÓVOA, A. Para uma formação de professores construída dentro da profissão. Revista de Educación, Madrid, n. 350, p. 203-218, set./dez. 2009. Disponível em: <http://www.revistaeducacion. educacion.es/re350/re350_09por.pdf>. Acesso em: 21 maio 2014.

OLIVEIRA, L. F.; CANDAU, V. M. F. Pedagogia Decolonial e Educação Antirracista e Intercultural no Brasil. Educação em Revista, Belo Horizonte, v. 26, n. 1, p. 15-40, abr. 2010.

PAGEL, R.; GROFF, P. V. Multiculturalismo: direitos das minorias na era da globalização. Revista IMES, Direito, São Caetano do Sul, v. 16, p. 7-19, 2009.

PIAGET, J.; SKEMINSKA, A. A gênese do número na criança. Rio de Janeiro: Zahar, 1975.

PIMENTA, S. G. O estágio na formação de professores: unidade teoria e prática. 5 ed. São Paulo: Cortez, 2002.

ROCHA, L. A. C. Projetos interdisciplinares de extensão universitária: ações transformadoras. Dissertação (mestrado) - Programa de Pós-Graduação em Semiótica, Tecnologias de Informação e Educação, Universidade Braz Cubas, Mogi das Cruzes, 2007. Disponível em: <http://www.usjt. br/proex/arquivos/produtos_academicos/leliane_rocha.pdf>. Acesso em: 22 maio 2015.

RODRIGUES, A. L. L. et al. Contribuições da extensão universitária na sociedade. Cadernos de Graduação - Ciências Humanas e Sociais, Aracaju, v. 1, n. 16, p. 141-148, mar. 2013.

SERRAZINA. L. A formação para o ensino da Matemática: perspectivas futuras. Educação Matemática em Revista, SBEM, São Paulo, a. 10, n. 14, p. 67-73, 2003.

SILVA, T. T. da. Documentos de identidade: uma introdução às teorias do currículo. Belo Horizonte: Autêntica, 2007.

SILVA, T. T. Os novos mapas culturais e o lugar do currículo numa paisagem pós-moderna. In: SILVA, T. T.; MOREIRA, A. F. (Ed.). Territórios contestados - o currículo e os novos mapas políticos e culturais. Petrópolis: Vozes, 1995.

TARDIF, M. Saberes docentes e formação profissional. Petrópolis, Rio de Janeiro: Vozes, 2014.

THIOLLENT, M. J. M. Construção do conhecimento e metodologia da extensão. João Pessoa: ICBEU, 2002.

TUBINO, F. La interculturalidad crítica como proyecto ético-político. In: ENCUENTRO CONTINENTAL DE EDUCADORES AGUSTINOS, 2005, Lima. Anais eletrônicos... Lima, 2005. Disponível em: <http://oala.villanova.edu/congresos/educación/lima-ponen-02.html>. Acesso em: 15 out. 2009 .

VERGNAUD, G. Théorie des champs conceptuels. Recherches en didactique des mathématiques, Paris, v. 10, p. 47-56, 1990.

WALSH, C. Interculturalidad Crítica/Pedagogia decolonial. In: MEMÓRIAS DEL SEMINÁRIO INTERNACIONAL. Diversidad, interculturalidad y construcción de ciudad. Bogotá: Universidad Pedagógica Nacional, abril de 2007. p. 17-19. 